\title{
Using Action Research To Improve Teaching And Learning
}

\author{
Christie L. Ahrens, Saint Xavier University \\ Mary Ellen Brant, (E-mail: brant@sxu.edu), Saint Xavier University \\ E. Suzanne Lee, (E-mail: slee@sxu.edu), Saint Xavier University
}

\begin{abstract}
This paper outlines the components of an action research project developed in a Master of Arts in Teaching and Leadership program designed to improve teaching and learning.
\end{abstract}

\section{INTRODUCTION}

aint Xavier University in Chicago, Illinois offers a Master of Arts in Teaching and Leadership (MATL) degree program for certified teachers in the state of Illinois. This professional development program is provided through a partnership with Pearson Achievement Solutions. The program employs an action research model to guide teachers in analyzing how they are teaching and how well their students are learning.

\section{ACTION RESEARCH}

Action research has been defined by Mills (2003) as any systematic inquiry conducted by teacher researchers for the purpose of gathering information to improve their teaching. A distinguishing feature of action research is that it is conducted by "teachers for themselves; it is not imposed on them by someone else" (p. 5). Models of action research have been developed by Lewin (1952), Kemmis (1988), Wells (1994), and Calhoun (1994), as cited in Mills (2003). Descriptors gleaned from analysis of various action research models can be summed up in three words: think, look, and act (Stringer, 1996).

\section{MATL MODEL}

As with other models, the MATL instructional model might best be described as a reflective loop. Components of this model are dynamic, on-going, cyclical, and representative of those outlined by Mills (2003) and other action researchers in the field of education. Methods of teaching action research in Saint Xavier University's MATL program are interactive and experientially based. Our students, all practicing teachers, are continually urged to ask questions, review differing strategies, and self-reflect as they engage in the practice of thinking, looking, and acting. We encourage them to "think out of the box" as they weigh alternatives to traditional instructional delivery. This paper describes and explains ways in which we urge and encourage our students to ask, consider, and reflect.

Although we are each well versed in theoretical perspectives of research, and we bring our own expertise to the classroom, our chief purpose is to engage our students in a continual quest for knowledge. As instructors who deliver this program, we consider ourselves teaching and learning coaches. Rather than standing and delivering information, we act as guides to promote significant personal and professional growth. In time, this immersion in ongoing inquiry serves to motivate teachers to pursue their own learning and positively impact student/teacher relationships.

As they are guided through this two-year graduate program, MATL students develop, articulate, plan, implement, and evaluate an action research project in their classroom. Over time, a four-step learning process surfaces as their underlying theoretical premise. As evident in Figure 1, this learning process is cyclical in nature. 
The outcome of their spiraling journey of learning, growing, and changing is a written thesis that reflects the product of these stages.

Understand

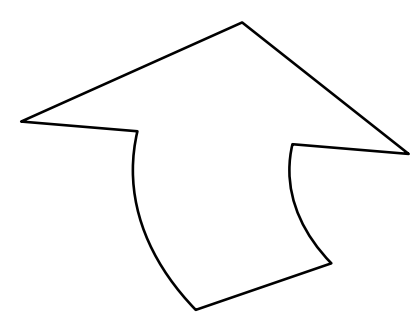

Take Action

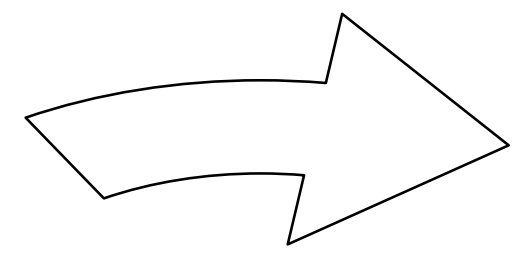

Four-Step Learning Cycle
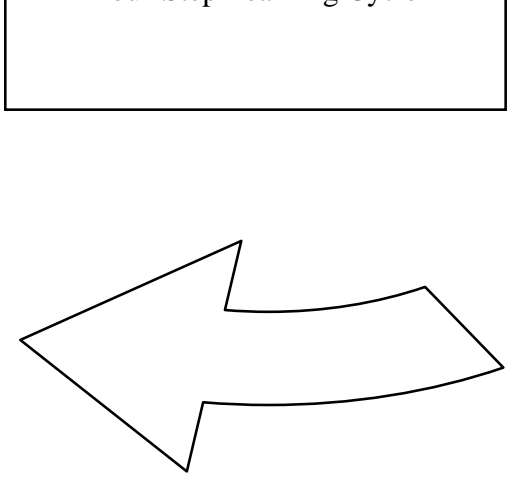

Figure 1: Four-Step Learning Cycle
Envision

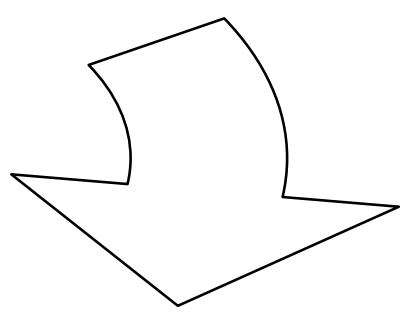

Get Real

Just as there are four distinct learning stages in this model, there are four chapters in the thesis document that our students produce. This paper presents the four steps of the learning cycle model by explaining each step, describing how MATL program requirements promote each stage and providing excerpts of a completed action research project.

\section{Understand}

MATL action research coursework begins with the notion of understanding. We must possess selfknowledge to understand our personal worldview. Knowledge of self informs us of the lens through which we see our world and therefore how we relate to others. By promoting and practicing conscious reflection, we hope students will increase their awareness of the cause and effect relationship between the way they act as teachers and the way their students react to them.

This conscious reflection is painfully evident in the beginning of the action research process as teacher researchers articulate the focus of their inquiry project. To accomplish the task of identifying their research issue, MATL students must ask themselves: What is my most problematic classroom situation? How am I contributing to this problem? What best practice strategies should I be using to help my students improve academic performance and our classroom environment? Questioning to promote conscious reflection often occurs in contrast to the teachers' familiar method of discussing issues. Traditionally, when sharing concerns, teachers identify external factors that are beyond their control; their mantra has been: My students come from low-income families, so I'm fighting a losing battle. My administrators don't follow up on anything; that's why my kids don't behave. We don't 
have the funding to get the literature books I need. What am I supposed to do without books? I don't have time to implement anything new; I have to spend too much time teaching to the test. The MATL program refocuses teacher researchers to concentrate on issues over which they have control and can effect change. Thus, they spend their time looking through the lens of self. They question what is happening in their classroom to better understand, and ultimately influence, the problems they have encountered.

In an effort to clarify the scope of their research problem, the MATL students' first task in the action research process is to gather data regarding the school and community in which they work. They begin Chapter 1 by evaluating the immediate context of the problem and their surrounding community. The teacher researchers use their respective school report cards to gain awareness of school, district, and state demographics for their students and colleagues, as well as study their students' test score performance. They analyze this data and consider the potential impact it has on their identified problem. Our experience in supervising action research projects has provided evidence that the majority of teacher researchers have never been directed to consider the larger context of demographics, community, or state and national trends as they relate to their classroom. The knowledge MATL students' gain from analyzing their demographics assists them to design programs to overcome inherent challenges in their teaching situation. When researching intervention strategies, and keeping their school demographics in mind, students might find they need to engage in differentiated instruction, design programs that will encourage parents to read to their children, and/or readdress their homework policy. Thus, they are able to refocus their energy and their discussions change: I can't control the number of low-income students I have or how many of my parents read to their children, but I can use the skills I am developing in this master's program to research methods to help me better meet the needs of my current population.

The action research project example used for this paper demonstrates that the teacher researchers (Iadipaolo, Olson, \& Seiver, 2006) do not find any immediate data concerns related to their specific school sites; however, upon further investigation, as required in the MATL program, they identify concerns related to teen literacy, vocabulary acquisition, and reading comprehension at the state and national levels. Even with their stable demographics and high-quality test scores in 2006, these teacher researchers cited the predictions of inevitable growth projected for the next 5 to 10 years. They recognized the need to utilize best practice teaching methodologies to further enhance current student performance and to prepare their teaching repertoire to better accommodate the influx and variety of the impending growth. For example, the teacher researchers identified the following problem: The students of the targeted secondary classes "exhibited reduced vocabulary usage and retention that interfered with reading comprehension, effective communication, and problem solving procedures and solutions" (p. 1).

Chapter 2 continues with the process of understanding the existence and probable causes of the problem. The first step in this two-stage process requires the teacher researchers to present data verifying the extent of their problem. The need for improvement in their classrooms is identified through tools such as pretests, surveys, and other assessments. This information serves as baseline data for the students' inquiry project. Questions teacher researchers must answer as they consider baseline collection tools include: How do I know this is a problem for my students? What evidence do I have that this problem exists in my classroom? Are their certain days, times, and/or situations that seem to cause the problem? In time, MATL students will prioritize teaching and learning issues that concern them and narrow their focus to topics within their locus of control.

For example, in their thesis, Iadipaolo, Olson, and Seiver (2006) found evidence for the existence of their problem through the use of "student self-evaluations, incomplete or incorrect student assignments, and lower quiz/tests scores and pretest assessments" (p. 1). Their research for probable causes led the three teacher researchers to the literature, which revealed a lack of vocabulary instruction for k-12 classrooms.

The second stage in determining probable causes for their problem requires the teacher researchers to search the professional literature in order to determine what knowledgeable others have found. The literature review promotes an understanding of their problem and its potential causes in the broader educational field. 


\section{Envision}

The notion of envisioning is associated with Covey's (1989) concept of "beginning with the end in mind" (p. 95). Whereas students were initially asked to focus on issues and concerns they observed within their educational environment to determine their inquiry problem, we now invite them to envision a best-case educational scenario. The MATL students begin this task by asking themselves: What is my vision of the "perfect" school or classroom? How would it feel to be a student or teacher there? What would my perfect school/classroom look and sound like? This is an opportunity for our students to acknowledge the wishes, hopes, and dreams they hold for their students and the educational system in which they teach.

As a culmination of their envisioning, Iadipaolo, Oslon, and Seiver (2006) determined that their project objective was to increase their students' "text comprehension and usage and retention of targeted vocabulary words within specified content areas" (p. 21). By beginning with the end in mind, they became consciously aware of what they hoped to accomplish by conducting their research project.

An important part of the envisioning step is to conduct a reconnaissance mission (Mills, 2003). During this mission, MATL students are encouraged to consider the following question: What if they really could make their vision a reality: What would it take? The answer to this question depends upon their review of the educational literature related to their problem. At this point, students investigate how others in the educational field have addressed their identified problem. This is the step where specific potential solutions are gathered, discussed, and determined. It is important for the teacher researchers to realize the breadth of solutions/strategies available throughout the field of education and to use their professional expertise to focus on strategies specific to their students, environment, and community. This portion of the literature review appears in Chapter 3 of the MATL students' action research thesis.

Following an extensive review of literature related to vocabulary acquisition in secondary school, Iadipaolo, Oslon and Seiver (2006) found "examples for providing ample opportunities for new vocabulary terms, including use of group work, class discussion, games, problem solving activities, and immersion within society" (p. 17). They also discovered that providing opportunities for students to practice vocabulary would allow them to integrate new words into their vocabulary.

\section{Get Real}

In order for students to achieve their project objective they must understand their current situation. The process of getting real, or evaluating, requires students to establish where they are in relationship to where they would like to be. This often involves a review of the baseline data they collected to provide evidence of their problem. At this stage students develop and articulate specific action steps they will take, and intervention strategies they will utilize, to accomplish their project objective(s). Here we ask them to identify the process necessary to accomplish their objective, as well as provide a menu of activities for each week of their research project so the project can be implemented.

Iadipaolo, Olson, and Seiver (2006) identified the following action steps for their research project:

1. Lesson plans and materials will be created which address multiple intelligences.

2. Special attention will be given to mnemonic devices and study skills to help with the memorization and retention of the target vocabulary.

3. Surveys and teacher checklists will be created and administered to monitor students' attitudes towards the effectiveness of multiple intelligences instructional strategies related to comprehension and understanding.

4. A variety of visual didactics will be implemented and displayed. (p. 21)

The three teacher researchers further articulated their project action plan to describe specific strategies they would be implementing. 
In the content area of mathematics, students studied "word roots, prefixes, suffixes, and word relationships to define, discuss, and relate words to mathematical content" (Iadipaolo, Olson, \& Seiver, p. 22). Gardner's (1993) multiple intelligences were addressed by combining verbal linguistic activities with visual spatial activities. To support interpersonal development they had their students record new vocabulary words in journals. Visual spatial and logical mathematical strategies were implemented through vocabulary cartoons and employing key word strategies. Graphic organizers were used to classify types of vocabulary words (Iadipaolo, Olson, \& Seiver, 2006). Examples of this learning stage (Getting Real) are documented in Chapters 2 and 3 of the completed action research thesis.

\section{Take Action}

Teaching and learning require action. After identifying their solution strategies through the review of literature, the teacher researchers spend a minimum of 10-12 weeks implementing these interventions in their classroom. Throughout their implementation period, MATL students document the process and take further action by gathering student data to evaluate the effectiveness of the strategies they implemented. Students share their research findings in Chapter 4. This final chapter of the research thesis requires MATL students to evaluate and interpret their data to determine to what extent project objectives were accomplished. In addition, students reflect on the action steps they followed to consider what they could have done differently, what they will continue as part of their instructional program, and what recommendations they would make for next steps.

Iadipaolo, Olson, and Seiver (2006) implemented their action plan for a period of 12-weeks. Analysis of their data demonstrated that the keyword method of vocabulary instruction, the use of semantic and graphic organizers, and interventions integrating vocabulary skills with Gardner's (1983) theory of multiple intelligences, caused a dramatic increase in their students' ability to learn, recall, and use targeted vocabulary. An improvement in students' attitude toward learning vocabulary was also evident. This improvement might be attributed to the fact that students were presented with strategies matching their learning styles. In addition, students were observed using many of the targeted words in their daily journal writing and essays. Immersion was taking place as students noticed vocabulary words outside the classroom in movies, conversations, and advertisements.

Chapter 4 concludes with a personal reflection narrative. In this section, we ask MATL students to contemplate their two-year journey and describe the evolution of their learning. This reflective expedition moves many of our students to a deeper understanding of their personal impact upon the system in which they teach.

\section{Completing The Loop: Understand, Envision, Get Real, And Take Action}

To complete the loop, MATL students reflect on the knowledge gained through their survey of the literature and their findings from the assessments administered at the conclusion of their action research project. Then, these reflections promote new understandings and open students to additional possibilities of action research projects to be implemented, evaluated, and to continue the loop of understanding, envisioning, getting real, and taking further action.

T.S. Eliot eloquently summarizes the spiraling nature of the MATL program and its foundational elements of learning: "We shall not cease from exploration and the end of all our exploring will be to arrive where we started and know the place for the first time." In her closing narrative, Seiver (2006) gives meaning to Eliot's words and brilliantly encapsulates the learning stages we strive to advance in our program:

When this journey began two years ago, I had no idea how much I would learn through using the action-research model. When my group chose to study vocabulary instruction and retention, I thought I already knew most everything about teaching it because I was, after all, an English teacher, and I had been teaching vocabulary for years. How naive I was! Not only did I learn a lot of new techniques for teaching vocabulary that I found to be extremely successful, I learned a lot about how to become a better teacher overall. 
I learned the importance of using current research. Like many, I felt pressured to find time to plan, organize, teach and assess students; where would I find time to read (boring) research? Besides, "research" is done by those who aren't in classrooms, so the "findings" are often theoretical instead of practical. How naive I was! Through using the action research model, I was "forced" to read the research that was out there not only on how to teach vocabulary, but why I needed to teach vocabulary, problems that could occur if vocabulary is not taught, and several potential solutions. Reading research caused me to question what I was doing in my classroom and to try other methods, and to look for better, more current solutions to my current problems. As a result, I find that I am reading more of my professional journals, and I've found that classroom educators write most of the articles and the suggestions and methods are practical!

Now that the action research project is complete, I no longer feel naive! I feel I am a more informed as well as better equipped to teach vocabulary. I know the importance of vocabulary and that it must be specifically taught. I have adopted numerous methods, especially the Keyword method, and expanded them for use in all of my classes. I am confident that would never have happened if not for the action research project. (Iadipaolo, Olson, \& Seiver, 2006, pp. 37-38)

\section{REFERENCES}

1. Covey, S. R. (1989). The 7 habits of highly effective people: Powerful lessons in personal change. New York: Fireside Books.

2. Gardner, H. (1983). Frames of mind: The theory of multiple intelligences. New York: Basic Books.

3. Iadipaolo, S.A., Olson, T., \& Seiver, M. (2006) Vocabulary instruction: A study of the effectiveness of using multiple intelligences. Unpublished master's thesis. Saint Xavier University, Chicago, Illinois.

4. Mills, G. E. (2003).Action research: A guide for the teacher researcher. Upper Saddle River, NJ: Pearson Education, Inc.

5. Stringer, E. T. (1996). Action research: A handbook for practitioners. Thousand Oaks, CA: Sage.

\section{NOTES}

